\title{
Histochemical and ultrastructural study of an elastofibroma dorsi coexisting with a high grade spindle cell sarcoma
}

\author{
M. Alberghini, P. Bacchini, G. Pignatti,* M.C. Maltarello," L. Zanella, N.M. Maraldi, ${ }^{\circ}$ F. Bertoni* \\ Department of Surgical Pathology, $* 7^{\text {th }}$ Orthopedic Ward, "Cellular Biology and Electron Microscopy \\ Laboratory, IOR and ${ }^{\circ}$ ITOI-CNR, Unit of Bologna c/o IOR, Bologna, Italy
}

(C)2004, European Journal of Histochemistry

Elastofibroma dorsi is a pseudotumoral fibroproliferative lesion characterized by polymorphic fiber-like deposits of elastinophilic material. Several theories have been reported explaining the pathogenesis of elastofibroma. Recent cytogenetic studies have demonstrated chromosomal instability in elastofibromas, not normally observed in non-neoplastic tissues. These chromosomal defects are commonly observed in aggressive fibromatosis too. Such clinical observations suggest a multistage pathogenetic mechanism for the onset of elastofibroma. This study, using histochemical, immunohistochemical staining techniques, and ultrastructural examination, describes the detection of an otherwise typical elastofibroma contextual to a high grade sarcoma. Hence, the coexistence of elastofibroma and high-grade sarcoma may suggest a causal link between the two pathological entities. The results obtained suggest that the coexistence of the two pathological entities is conceivably coincidental.

Key words: elastofibroma, pseudotumoral lesions, leiomyosarcoma.

Correspondence: M. Alberghini, Anatomia Patologica, Istituti Ortopedici Rizzoli, via di Barbiano 1/10 40136 Bologna, Italy.

Phone: international +39.051 .6366593 .

Fax: international +39.051.6366592

E-mail: marco.alberghini@ior.it

Paper accepted on November 17, 2003

European Journal of Histochemistry 2004; vol. 48 issue 2 [Apr-Jun]: 173-178
E lastofibroma is a well-defined pseudotumoral lesion, first described as a tumour originating from elastic tissue (Jarvi and Saxen, 1961). It belongs to the heterogeneous group of fibroblastic proliferations, most of which are considered reactive rather than neoplastic processes (Enzinger and Weiss, 1995). Once believed to be rare, elastofibroma is now known to occur in 24 percent of women and in 11 percent of men over 55 years of age, as an incidental finding at autopsy (Jarvi and Lansimies, 1975). Its typical location is between the lower end of the scapula and the chest wall, and characteristically appears as an ill-defined mass in the infrascapular region. This lesion occurs bilaterally in about $10 \%$ of cases and rarely in other anatomic locations. The interpretation of elastofibroma as a malignant tumour has raised increasing interest. Originally considered to be a reactive lesion due to friction between the end of the scapula and the thoracic wall (Jarvi and Saxen, 1961), elastofibroma is now thought to be a pseudotumoral lesion with a multifactorial pathogenesis; environmental conditions, such as manual labour, act on chromosome instability ( $\mathrm{McC}$ omb et al, 2001), causing the onset of the lesion, through an enzymatic defect, and then abnormal elastin production (Fukuda et al, 1987; Barr, 1966). These clonal abnormalities are more typically neoplastic than reactive.

In this study we examined, by histochemical and ultrastructural analyses, a typical elastofibroma dorsi occurring in a patient presenting a high-grade leiomyosarcoma, in order to verify the possibility of a causal link between these two pathological entities.

\section{Materials and Methods}

The bioptic material was obtained from the same patient, a 64 year old woman. Histological examination of the first lesion revealed a grade 4 spindle- 


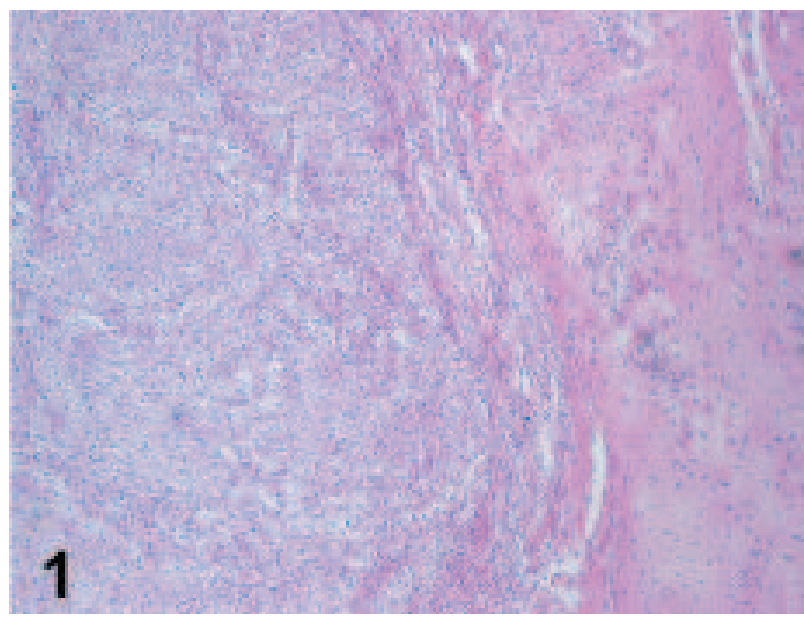

Figure 1. Paraffin section; ematoxylin eosin stain. Leiomyosarcoma grade 3 with fascicular growth pattern (central nodule), surrounded by a fibrous-fatty tissue (elastofibroma). X 100.

cell sarcoma. The second one was obtained three months later at the site of a local recurrence. The specimens were formalin fixed and paraffin embedded. $3 \mathrm{~mm}$ sections were stained with ematoxylineosin and histochemical Weigert stain for elastic fibers, and examined under a light microscope. Immunohistochemical analyses were performed using the following antibodies: anti-vimentin monoclonal, clone V-9 dilution 1:200; anti-human smooth muscle actin, clone $1 \mathrm{~A} 4$, prediluted; antihuman muscle actin, clone HHF-35, prediluted; anti human desmin, clone D-33, prediluted; and rabbit anti-cow S-100, polyclonal, dilution 1:400. For ultrastructural studies the samples were fixed in $2.5 \%$ glutaraldehyde in $0.1 \mathrm{M}$ sodium cacodilate buffer $(\mathrm{pH}, 7.2)$ for 3 hours at $4^{\circ} \mathrm{C}$. The specimens were post fixed in $1 \%$ osmium tetroxide in Veronal buffer for 1 hour at $4{ }^{\circ} \mathrm{C}$, dehydrated in a graded alcohol series and embedded in Epon 812 epoxy resin. Thin sections were stained with uranyl acetate and lead citrate. The sections were examined with a ZEISS EM-109 transmission electron microscope.

\section{Results}

The surgical specimen of the recurrent disease showed a central nodule mainly composed of spindle cells, arranged in a storiform fashion (Figure 1). Nuclei were hyperchromatic, with prominent nucleoli and high mitotic rate. Atypical mitoses were also present. Immunohistochemistry showed positivity for vimentin, human muscle actin and smooth muscle actin in the neoplastic spindle cells
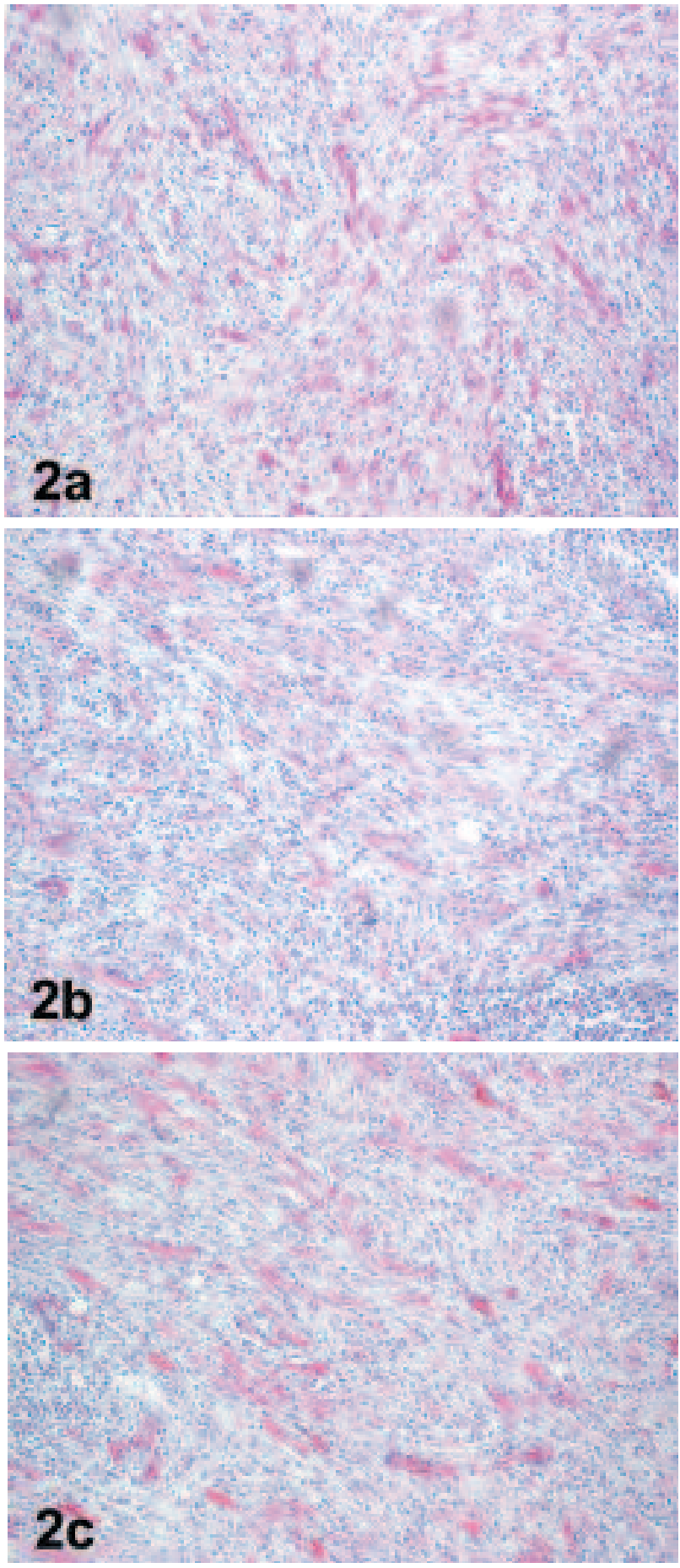

Figure 2a-c. Central nodule (leiomyosarcoma). Focal positivity of the neoplastic spindle cells. a. anti-vimentin; b. anti-actin-G; c. anti-actin-L. X 200.

(Figures 2a-c). Antibodies against desmin and S100 protein were negative (not shown). The ultrastructure of the spindle cells of the central nodule revealed the presence of typical myofibroblasts characterized by aggregates of cytoplasmic fila- 


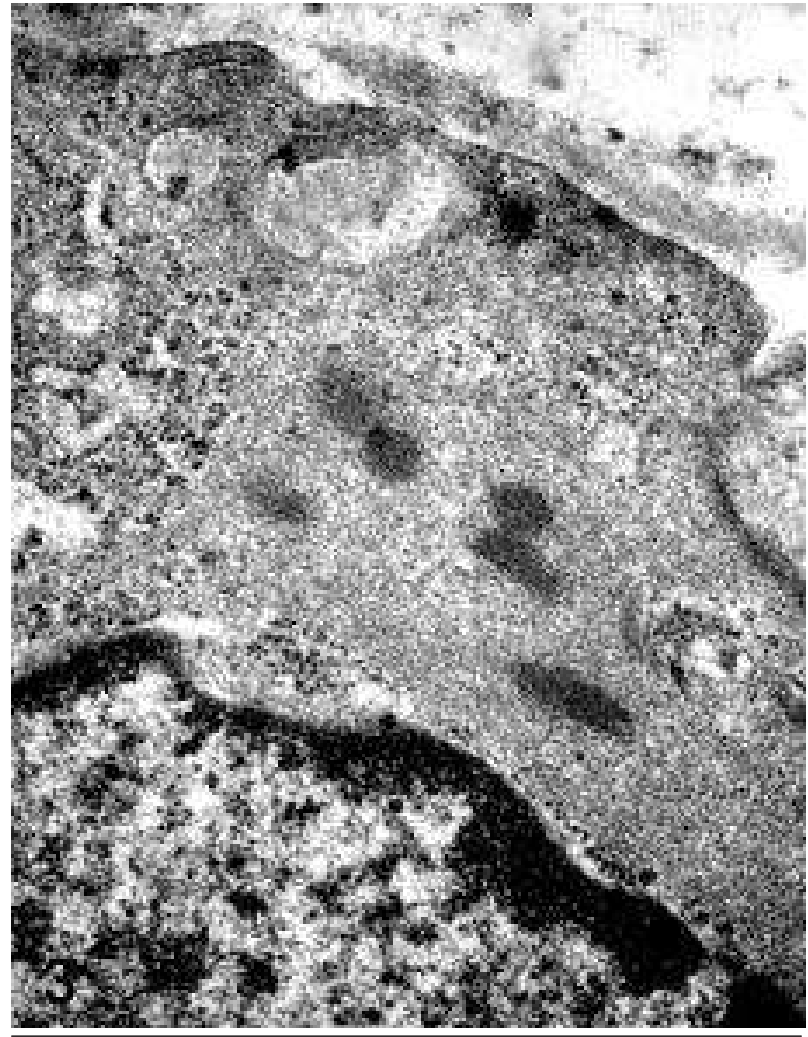

Figure 3. Detail of an aggregate of filaments in a leiomyosarcoma cell. Note the presence of focal densities in the intracellular filament aggregates. X 32,000.

ments 6-8 $\mathrm{nm}$ in thickness and distinct focal densities (Figure 3). The fibro-fatty tissue surrounding the tumoral nodule was unusually rich in refractile fibers (Figure 1). Histochemical Weigert stain for elastic tissue confirmed their nature (Figure 4). The diagnosis of grade 3 leiomyosarcoma contextual to elastofibroma was made. Ultrastructural examination, performed in the fibro-fatty tissue surrounding the tumoral nodules, showed typical characteristics of an elastofibroma. The collagen fibers of the stroma were normal and had a uniform diameter. The fibroblasts were elongated with thin, irregular processes extending between the collagen bundles. They showed an oval nucleus with an often indented profile, marginated heterochromatin, thickened nuclear fibrous lamina adjacent to the inner nuclear membrane, and an abundant rough endoplasmic reticulum with dilated cisternae (Figure 5). Abnormal elastic fibers surrounded by electron dense material were also present; this peculiar structural feature gave the fibers a typical moth-eaten configuration (Figure 6). Particular attention was given to a cell population present in the context of the fibrous tissue surrounding the

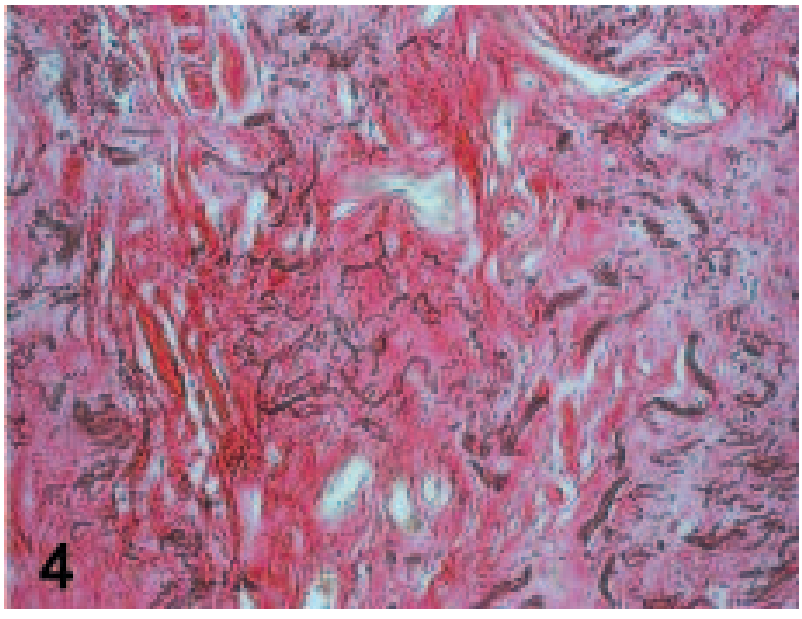

Figure 4. Fibrous-fatty tissue surrounding the nodule (elastofibroma). Histochemical stain for elastic fibers (Weigert) reveals branched and unbranched structures, with undulating pattern, embedded in interlacing collagen fascicles. X 200.

nodules. These cells, in fact, were characterized by indented nuclei and large aggregates of cytoplasmic filaments 6-8 $\mathrm{nm}$ thick (Figures 7,8). These myofibroblast-like cells, however, did not show focal densities in the myofilament aggregates nor association with the plasmalemma, typical of leiomyosarcoma cells (Enzinger and Weiss, 1995), present in the central nodule cells (Figure 3 ).

\section{Discussion}

The hypotheses on the pathogenetic mechanisms of elastofibroma have constantly changed since its original description. This reactive lesion was initially considered the result of an abnormal elastogenesis (Jarvi and Saxen, 1961), and later as hypertrophy of elastic fibers followed by degeneration and resorption (Jarvi et al, 1969). Stemmerman and Stout (1968) interpreted elastofibroma as a elastotic degeneration of pre-existing elastic fibers; Winkelmann and Sams (1963) considered elastofibroma as an elastic tissue dysplasia, with excessive formation of elastic tissue by fibroblasts; Akhtar and Miller (1977) explained elastofibroma as an arrested development of elastin fibers; Kahn and Hanna (1995) hypothesized an exaggerated foetal elastin production. The prevailing location of elastofibroma in the subscapular region, suggested that repeated trauma due to the friction between the scapula and the chest wall could be involved in the elastofibroma pathogenesis. An enzymatic defect as the possible cause of an abnormal production of elastin has also been suggested (Barr, 

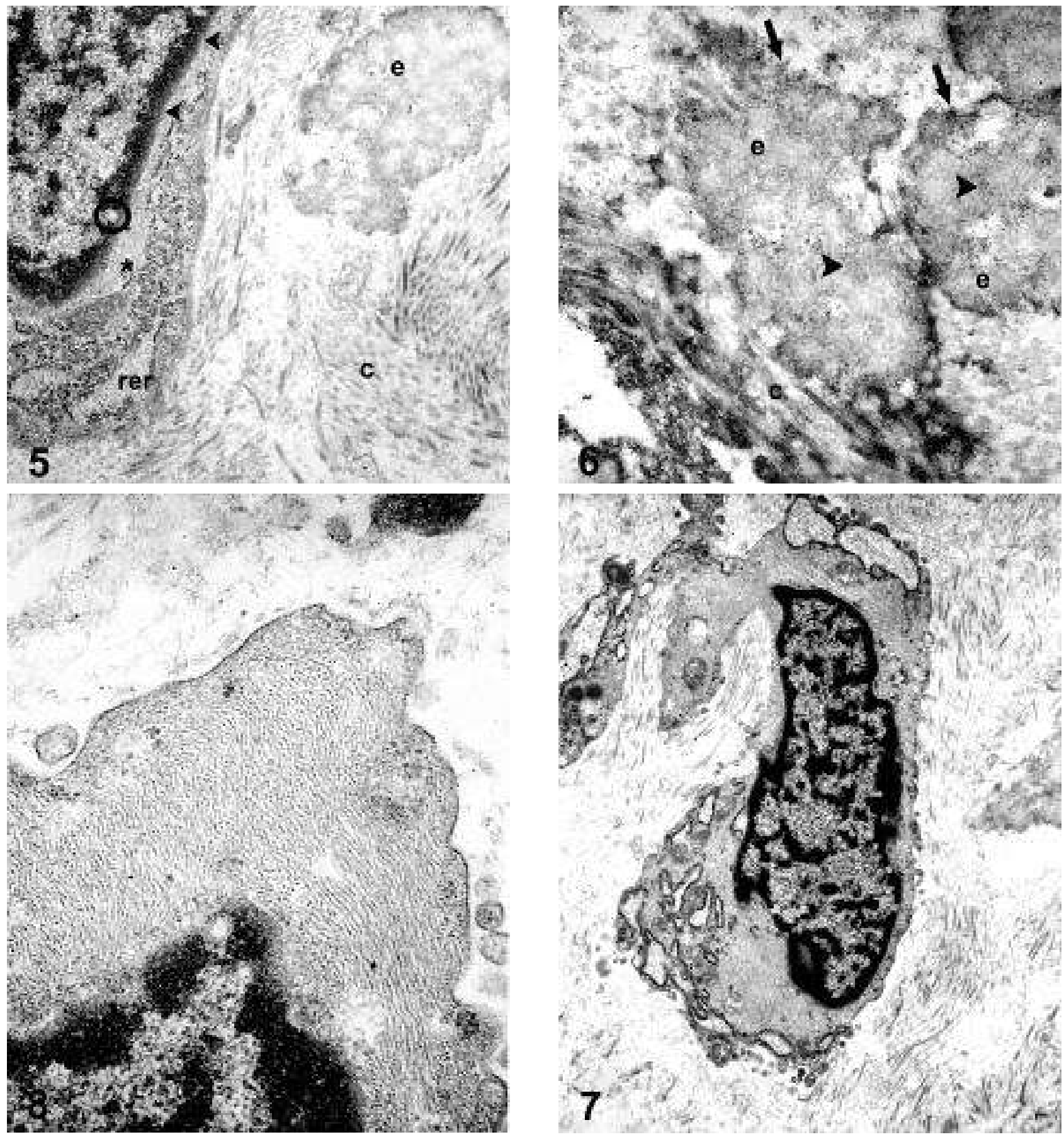

Figure 5. Electron micrograph of a fibroblastoid cell. Note the nuclear chromatin surrounded by a well-developed fibrous lamina (arrowheads) present within the inner nuclear envelope. Fibrous lamina is interrupted by the nuclear pores (_). rer = prominent rough endoplasmic reticulum; ' = presence of numerous cytoplasmic filaments. Amorphous elastinophilic masse (e) and collagen (c) are in close proximity to the fibroblast-like cell. X 18,000.

Figure 6. Electron microscopy of the elastofibroma. Abnormal elastic fibers surrounded by electron dense material giving the peculiar "moth-eaten" configuration to the edges of the fibers (arrows). Note the paler staining elastin (e) and the dense zones (') which probably represent filaments trapped within the elastin. $c=$ collagen. $X 32,000$.

Figure 7. Electron micrograph of a myofibroblast-like cell in the elastofibroma. The cytoplasm is rich in aggregates of 6-8 $\mathrm{nm}$ thick filaments and of enlarged cisternae of the endoplasmic reticulum. The nucleus presents indentations and peripheral masses of heterochromatin. X 11,000.

Figure 8. Detail of an aggregate of filaments in a myofibroblast-like cell in the elastofibroma. The 6-8 nm thick filaments are uniformly distributed in the cytosol and do not show focal aggregates or association with the plasmalemma. X 42,000. 
1966; Fukuda et al, 1987). This biochemical defect could explain the onset of elastofibromas in eye, omentum, and bilateral location ( $\mathrm{Hsu}$ et al, 1997; Malaterre et al, 1995; Nagamine et al, 1982; Tsutsumi et al, 1985). Recent cytogenetic studies have discovered chromosomal instability in elastofibromas, not normally observed in non-neoplastic tissue (Vanni et al, 1999). The short arm of chromosome 1 was the region most frequently involved, especially band 1p32. These structural changes are common with desmoid tumour, a locally aggressive pseudotumoral fibrous proliferation. Elastofibromas show additional translocations involving chromosomes 8 and 12 (Mc Comb et al, 2001). These observations of clonal abnormalities suggest that elastofibroma may represent a first step toward neoplastic transformation. The coexistence of an elastofibroma with a grade 3 leiomyosarcoma, reported in this study, could suggest a link between the two pathological entities. Elastofibroma, in fact, might represent a first step toward the onset of a malignant neoplasm. The present investigation was aimed to identify cells with characteristics of the leiomyosarcoma within the elastofibroma tissue surrounding the recurrent leiomyosarcoma nodules. The results obtained confirmed that the central nodule, containing pleomorphic spindle cells with hyperchromatic nuclei, positive for vimentin and smooth muscle actin, was a typical grade 3 leiomyosarcoma. Ultrastructural analysis confirmed the presence of typical aggregates of actin filaments within the cytoplasm of the leiomyosarcoma cells, charcterized by focal densities and close association with the plasmalemma. On the other hand, the fibro-fatty tissue surrounding the recurrent nodules, particularly rich in elastic fibers, showed the characteristics of the elastofibroma, with a cell population of fibroblasts and typical moth-eaten elastic fibers. A further cell population, showing some characteristics of myofibroblasts, might suggest an evolution toward the malignant neoplasm. However, the absence of typical focal densities and association with the plasmalemma in the filament aggregates in these cells suggests that they represent a distinct cell population of myofibroblasts within the elastofibroma. Consequently, we are inclined to believe in a purely coincidental coexistence of the two pathological entities.

\section{References}

Akhtar M, Miller RM. Ultrastructure of Elastofibroma. Cancer 1977; 40:728-35.

Barr JR. Elastofibroma. Am J Clin Pathol 1966; 45:679-83.

Enzinger MF, Weiss S.W. Benign fibrous tissue tumors. In: Soft tissue tumors. Mosby, St. Louis; $3^{\text {rd }}$ edition. 1995. p. 187-91.

Fukuda Y, Miyake H, Masuda Y, Masugi Y. Histogenesis of unique elastophilic fibers of elastofibroma: ultrastructural and immunohistochemical studies. Hum Pathol 1987;18:424-9.

Hsu JK, Cavanagh HD, Green WR. An unusual case of elastofibroma oculi. Cornea 1997;16:112-9.

Jarvi OM, Saxen AE. Elastofibroma dorsi. Acta Pathol Microbiol Scand 1961;51:83-95.

Jarvi $\mathrm{OH}$, Lansimies $\mathrm{PH}$. Subclinical elastofibromas in the scapular region in an autopsy series : additional notes on the aethiology and pathogenesis of elastofibroma pseudoneoplasm. Acta Pathol Microbiol Scand 1975;83:87-108.

Jarvi OH, Saxen AE, Hopsu-Hayu VK, Vartovaara JJ, Va'issalo VT. Elastofibroma. A degenerative pseudotumor. Cancer 1969;23:4263.

Kahn HJ, Hanna WM. "Aberrant elastic" in elastofibroma: an immunohistochemical and ultrastructural study. Ultrastruct Pathol 1995; 19:45-50.

Malaterre HR, Daver L, Djiane P. Myocardial infarction and cerebrovascular accident complicating papillary elastofibroma of the mitral valve. Presse Med 1995;24:1401-9.

McComb EN, Feely MG, Neff JR, Johannson SL, Nelson M, Bridge JA. Cytogenetic instability, predominantly involving chromosome 1 , is characteristic of elastofibroma. Cancer Genet Cytogenet 2001;126: 68-72.

Nagamine N, Nohara Y, Etsuo I. Elastofibroma in Okinawa. A clinic pathologic study of 170 cases. Cancer 1982;50:1794-805.

Tsutsumi A, Kawabata K, Taguchi K, Doi K. Elastofibroma of the greater omentum. Acta Pathol Jpn 1985;35:233-41.

Vanni R, Marras S, Faa G, Uccheddu A, Dal Cin P, Sciot R, Samson I, Van der Berghe H. Chromosome instability in elastofibroma. Cancer Genet Cytogenet 1999;111:182-3.

Winkelmann RK, Sams WM. Elastofibroma. Report of case with special histochemical and electronmicroscopic studies. Cancer 1963; 23:406-15. 
M. Alberghini et al. 